\title{
A Trans-Cultural Wisdom Bank in the Classroom: Making Cultural Diversity a Key Resource in Teaching and Learning
}

\author{
Dr Jui-shan Chang \\ Sociology Program, Department of Political Science, University of Melbourne
}

\begin{abstract}
:
This article presents an account of how I have made cultural diversity a powerful pedagogical resource for my teaching rather than a burden. I suggest that such an approach can deliver real educational benefits, rather than simply being a protocol to meet the requirements of 'political correctness' or commercial imperatives. The issues I have addressed include how and why: (a) I mobilise cultural diversity and a comparative perspective in my curriculum; (b) I propose the notion of 'trans-cultural wisdom bank'; (c) I bring cultural diversity into students' active learning which is achieved with intellectual depth and personal engagement; and finally (d) I demonstrate with a learning infrastructure of group work and a 'super-structure' of cultural contrasts to generate surprises and provoke new thoughts and discovery.
\end{abstract}

\section{About the author:}

Dr Jui-shan Chang grew up in Taiwan and received a PhD in Sociology from University of Michigan. She has researched Eastern and Western cultural configurations and experiences of sexuality, life course transitions, changing formations and meanings of love, marriage, family and manhood/womanhood. Her work has involved the development of the "Trans-cultural Wisdom Bank", which identifies wisdoms and possibilities from different cultural contexts to deal with human conditions and life course transitions in a globalized world.

Keywords: trans-cultural wisdom bank; cultural diversity; comparative perspective; group work; pedagogy. 


\section{A Trans-Cultural Wisdom Bank in the Classroom: Making Cultural Diversity a Key Resource in Teaching and Learning}

\section{Introduction}

In recent years, a welcome development in many universities in Western countries has been the promotion of 'cultural diversity' policies in relation to teaching and learning. Given the growing trend toward 'exporting' higher education from these countries to students in non-Western countries, an openness to cultural diversity is opportune. As an academic at University of Melbourne where at least a quarter of students are from overseas, particularly Southeast Asia, I have been aware that many colleagues at this university feel concerned about the impact of these developments on their teaching. While appreciating that such policies are essential if universities are to play a significant role in a rapidly changing and globalizing world, they naturally wonder how they are to take on this additional 'burden' of internationalising curricula and promoting cultural diversity on top of everything else in their routine workloads. A requirement for diversity seems like a burden, not an opportunity.

In this article, I would like to share with readers an account of how I have made cultural diversity a key resource in my teaching rather than a burden, and suggest that such an approach can greatly enhance the educational benefits, rather than simply meeting the requirements of 'political correctness' or commercial imperatives.

'Cultural diversity' is not something to be imposed or engineered, it is already there - it only needs releasing and harnessing. I have tried to do this by developing what I call a 'trans-cultural wisdom bank'. A 'trans-cultural wisdom bank is a conceptual metaphor that describes the eliciting, reflecting, pooling and exchange of cross-cultural insights and experiences about problems and issues that affect all humans. I believe that the ideas, principles and pedagogy involved in my teaching in Sociology Program at University of Melbourne are transferable to teaching and learning in other disciplines and in other universities in this globalizing world. Such a 'wisdom bank' relates to issues and problems, not simply 'perspectives'. It thus puts the emphasis on engagement with an issue (realism) rather than simply encouraging a mishmash of perspectives and a right of each to be articulated in general (relativism).

I started to teach sociology at the University of Melbourne in 1997. Previously, I had taught in Taiwan, at the University of Michigan, the University of Iowa and the University of Tasmania. Through all the years of teaching in three different continents, I have always been interested in the cultural diversity of my students, diverse cultures as social issues, and the power of a comparative perspective as part of my teaching and students' learning.

\section{Why do I mobilise cultural diversity and a comparative perspective in my curriculum?}

To me as a university teacher, cultural diversity is not only a worthwhile aim in itself but also it can drive learning towards excellence. In teaching all my courses, I always put cultural diversity and a comparative perspective at the core, because exposure (to 
diverse cultures) combined with reflection (through comparison and contrast of the different cultures and students' own cultures) can enable learners:

- to develop non-ethnocentric views about social issues in their own lives;

- to enjoy the sheer intellectual adventure of breaking out of the comfort, or the 'taken-for-granted' of their own culture, because such cultural contrasts generate surprises which stimulate students' minds and provoke new thoughts and discovery;

- to discern what is of value within their own culture and what is of value in other cultures; and, therefore,

- to understand not only 'other' cultures better, but to understand themselves better.

\section{Why do I propose the notion of 'trans-cultural wisdom bank'?}

Through a decade of cross-cultural comparative research, I have developed the idea of what I call a 'wisdom bank'. A 'wisdom bank' is the collection of the 'set' of possible 'solutions' from many different cultures or societies to recurrent problems that are common to the human condition, and which no one culture has (ever) managed to solve completely. A 'trans-cultural wisdom bank' broadens students' views in terms of a larger range of possibilities about important issues in everyday life. Anyone with an 'insight' about how a problem is solved can 'deposit' it in the bank and, in turn, on taking such insights back out, can find them enriched by other contrasting associated insights into the same problem.

For example, individuals in every culture have anxiety about transitions in life or in family (such as transitions to adulthood, sexual experience, marriage, parenthood, menopause, old age and death). Every culture or civilisation has wisdom about all these transitions and defines human nature and the meaning of love, relationships, marriage, family, manhood and womanhood. But many individuals still suffer problems related to these crucial life issues or transitions. For example, the divorce rate is up to 50 per cent in many western countries and divorce rates have also been increasing in many nonwestern countries. Obviously, to many people, their ancestors' wisdom does not seem to be working any more. Also, many countries since the $20^{\text {th }}$ century have been experiencing, and trying to deal with, the impacts of rapid social change (industrialisation, urbanisation, expansion of education, secularisation and globalisation) on family and individual life courses, on the value of education, on the role of government, and so forth.

Therefore, through comparison and contrast, a 'trans-cultural wisdom bank' will collect and reflect on all possible solutions to recurrent human problems from different cultures and subcultures. So, when people in any culture or society 'get stuck' on a certain issue in their own culture, they can look for alternative wisdom from this bank. Of course, these days in Australian classes, students generally come from diverse backgrounds and thus have access to the source of some elements of specific cultural wisdom.

The 'trans-cultural wisdom bank' is a new concept, which I introduce to all my students on the first day of a course, regardless of the subject matter. I have used this orientation in:

- introductory sociology;

- research methods; 
- statistics; and

- courses on marriage, family and sexuality.

In the first tutorial of every course, students are invited to introduce themselves in terms of the different cultures of which they are a part. 'Cultural diversity' refers not only to cultures from different world civilisations across different societies, but also to cultures or subcultures within a society, which could be a result of different ethnicities, regions, classes, genders, generations, religions, rural/urban settings, sexual orientations, etc. They are informed that they will be drawing on their own backgrounds and those of students from different cultures throughout the course, and that the more diverse their range of reference, the more they will learn. This factor is a key criterion in the assessment of the subject.

Students are encouraged to look around the classroom and feel excited (rather than scared, alienated, or invaded) when they see students from a wide range of different backgrounds. The metaphor of the wisdom bank is used consistently throughout the course and is built in to all the teaching procedures and assessment. For example, examination questions typically ask students to present arguments in relation to their reflection on their own culture(s) and those of their fellow students.

\section{How have I brought cultural diversity into students' active learning?}

With students excited about the idea of a trans-cultural wisdom bank and the diverse backgrounds of their classmates, there is already a firing-up of motivation: the reign of textbooks and the received 'academic wisdom' will not, alone, do. Where to go from here? How exactly do I encourage students to move beyond the comfort zone of the 'taken-for-granted' world within which they have grown up? Two pedagogical strategies have proved to be most effective.

\section{A learning infrastructure of group work}

The first pedagogical strategy is using a learning 'infra-structure' of group work, in which students from different backgrounds work and confront issues together. Students are required to form study groups from the first day of tutorials and each study group is to be composed of three members from different cultural or sub-cultural backgrounds. This study group is fixed through the whole semester - for conducting group projects outside of classroom and discussions in the tutorial sessions. Due to the concept of the 'wisdom bank' having being reiterated since day one, students know that it is to their advantage if their group's members are from very diverse backgrounds - the more diverse, the better. The students make their own choices for these groups, but the tutor has a role in assisting and overseeing the process of group formation.

Students don't mind revealing personal information regarding religious affiliation, class background (of their parents or grandparents), age or (even) sexual orientation. This sort of personal information may seem sensitive but, in my classroom, students know that such information is a 'plus' in forming a study group in which difference is valued. In this structure, no students need to feel strange, foreign, isolated, or discriminated against, because every student is different and is encouraged to be proud of being different (even if they may look 'the same', for example, 'white' or 'Asian'). In 
addition, students respect one another (regardless of what backgrounds they are from), wanting to draw wisdom from one another's 'bank' and deposit more wisdom into a common/joint account for their learning. The more that is put in, the richer this bank becomes.

\section{A 'super-structure' of cultural contrasts to generate surprises and provoke new thoughts and discovery:}

This aspect involves using:

- cross-national survey data;

- group members' biographical experiences; and

- cultural artefacts (eg films, magazines, newspapers).

In my research methods course, students have access to a cross-national survey data bank which they analyse according to their interests. I developed this innovative system (entitled Social Data Interchange (SDI): A System for Globally Oriented and Data Grounded Social Science Teaching and Research) with the support of the University of Melbourne, through a multi-media innovation grant. Utilising the SDI system, students develop ideas and arguments on important social issues and test them with real data from a range of countries. I have located and purchased good quality and important survey data sets relevant to social science courses. The data include nine surveys from 22 countries, with 170 variables and 1,000-4,000 cases per country. The total number of cases stored in my SDI engine is 141,846. The topics include social inequality and justice, role of government, social networks and support systems, family and gender roles, life style, work orientation and religion. This database and the relevant codebooks are currently located at the server of the Political Science Department at the University of Melbourne.

More generally, there have been several major cross-national surveys being conducted and archived in past decades. For example, a visit to a site like http://www.worldvaluessurvey.org reveals a gateway to surveys conducted across the globe on a vast array of issues. If students have an essay to do on Islamic views of government, they can do relevant analyses in which a range of attitudes to government can be related to various socio-demographic variables of respondents in various Islamic countries. Further, the relationships between respondents' socio-demographic backgrounds and their views of government in Islamic countries can be compared with such relationships among self-identified Moslem respondents in non-Islamic countries. More generally, there are now major social survey data archives with surveys on topics like politics, religion, work, education, gender, family, and environment, from which students can feel, witness, explore, and analyze the rich variety of problems and perceptions that abound across different countries and cultures. These data archives are increasingly accessible - just via a browser! In addition, students do not even need to rely on a statistical software package to conduct data analysis in a computer lab or on their personal computers, instead they can conduct relevant analyses on the data archive servers.

In their assessed work, students are required to analyse data from at least two or three different countries. The more diverse the group, the more resources ('wisdoms') students have to draw from and make sense of various trans-cultural contrasts. In 
addition to the impersonal, quantitative survey data, I also encourage group members to link projects and tutorial discussions to their own and their families' biographies. This provides a compelling forum within which complex ideas about social change, social structure, dynamics of social process and the boundaries of major social institutions can be illustrated with material and experiences relevant to the students.

For example, in the Comparative Family course, a typical tutorial involves the students in groups presenting meanings and core values from their different cultural backgrounds, for example in relation to a topic of marriage. Next, group members from different backgrounds reflect on, and compare and contrast, their experiences. In presenting their conclusions to the class, they are expected to provide an overview of these diverse contributions, and use them to generate theoretical arguments. They are then asked to link these arguments to existing theory.

In the first year introductory sociology course, each group must conduct field work involving interviews with people from diverse backgrounds, for a topical issue in which the group is interested. Again, the value of the exercise and the quality of the work produced are dependent on students developing an awareness of the cultural diversity issues that emerge from the interviewee backgrounds, as well as their sensibilities to be able to interpret the data.

In terms of cultural contrasts through cultural artefacts, for example, last year I took my class 'Love, Family and Sexuality - A Comparative Perspective' to a private viewing of the Italian film 'Life Is Beautiful' to compare it with a Chinese film 'To Live'. Students related to the 'everyday life' events in these films - even if those events were in two different historical-cultural-political contexts from their own. Students were in threeperson working groups for this project. They had to develop their own set of response sheets to reveal the key contrasts in the two films. Students were encouraged to generate their own insights and arguments on the meanings of love as well as the nature of the bond between family members, and the survival of the family in times of extreme political turmoil, which these two award-winning foreign films depicted.

\section{Active learning is achieved with intellectual depth and personal engagement}

Through personal engagement with many cultural contrasts, cultural shocks or surprises, students develop their own insights and then feel confident about their insights- having discussed them within ethnically diverse groups- and are then required to link their insights to the readings and arguments within the discipline.

These procedures make it impossible for the students to simply copy, echo or 'quote' authoritative texts. They are required to create arguments or theoretical insights from themselves and each other, insights which are essentially related to their personal identities. The learning is internalised, not forgotten as soon as the course has finished. In other words, intellectual depth and personal engagement occur together through this kind of active learning.

\section{Advantages of group work in general:}


The advantages of students from different cultural backgrounds working together are available to all students in any subject. Group work can allow students from different cultures or subcultures to be exposed to different learning, thinking and working styles or approaches to accomplish certain tasks. For example, students from some Asian cultures may tend to be quiet in learning but disciplined and focused in completing the tasks. They can learn about active sharing and expressing their ideas from students growing up in Western contexts by not being so conscious of the problem of 'losing face' and accepting that there is no such thing as 'face' in the learning process. Students growing up in the Western education system can also learn from Asian students in terms of different attitudes toward learning, working and self-discipline, and the values of education in general.

\section{b) Students learn to work as a team in a diverse group}

Experience in interacting and working with people from different backgrounds is crucial for developing students' capability for constructive team work. It is widely accepted that team work is a crucial part of most occupations in the contemporary workforce, and in that workforce the members of project groups are likely to be drawn from a wide range of different backgrounds. This becomes increasingly important as Australia (and many other societies in general) becomes more diverse in its ethnic composition and as it interacts more with the region and the rest of the world.

\section{c) This method provides an effective structure for students' learning and social life in a big university}

Very often, one pleasing by-product of group work is that students from different backgrounds become friends. They not only work together but also have a social life together. This helps tremendously to reduce the anxiety many students (whether domestic or international) experience in a new learning context, and to eliminate the isolation and alienation many experience in a big university.

\section{Conclusion}

We all can draw on the cultural diversity in our classrooms to introduce a valuable comparative perspective in teaching and learning, rather than seeing it as an extra burden to teachers or a barrier to students. Both teachers and students, regardless of their cultural or sub-cultural backgrounds, are conscious of the cultural diversity in the classroom. Under the right conditions, they can feel proud of their uniqueness and value that of others - enjoying the richness of the 'wisdom bank'. The interest in their own lives is what enables the 'deposits' to grow. The 'profit' lies in their enhanced capacity to deal with their everyday lives and futures in a multi-cultural environment and a globalised world.

\footnotetext{
${ }^{1}$ A brief summary of student feedback is attached in Appendix 1.
} 
This paper is a post-print version of an article published in the Journal of Studies in International Education, v10, n4 2006 - http://jsi.sagepub.com/

\section{Appendix 1: Feedback from Student Evaluations}

Below is a summary of responses from students relating to the three courses:

I. Love, Family and Sexuality - A Comparative Perspective (a $2 \mathrm{nd} / 3 \mathrm{rd}$ year course, 50 students)

II. Introduction to Quantitative Research Methods (a 2nd/3rd year course, 38 students)

III. Doing Sociology (a first year course, 130 students)

The overall mean score on the item 'The subject was well-taught' was 4.5 (on a fivepoint scale ranging from strongly disagree $=1$ to strongly agree $=5$ )

Analysis of written comments revealed widespread high levels of:

1. Interest ('stimulating', 'thought provoking', 'intense', 'very unique!')

2. Enjoyment ('fun', 'amusing')

3. Perceived positive impact on the development of knowledge and skills thought to be useful for both careers and life in general

Other patterns of responses are represented by the following quotes:

'Comparative perspective stimulates us into thinking about life, love, family and sexuality issues which we may not have thought of before...'

'... gives insights into other cultures and my own culture, good knowledge.'

'... I believe it provides useful skills for career prospects.'

'... extremely interesting but also very useful.'

'It makes you more aware of what is happening around you. (It) was the most relevant and interesting all my subjects so far at university.'

'... it provides a very clear-cut pathway towards contributing to social research and empower(ing) students.'

'... it gives you valuable skills that can be used outside the sociological context. Also, gives good insight to the workings of our society.'

'... it was a good grounding for professional jobs and practical application to our daily lives.'

'... practical 'doing' aspect helped put abstract themes in context.'

'... good issues were raised and it made me think and reflect about society and my life.' 
'... working in groups has helped establish more connections with classmates, which is good and makes class comfortable.'

'The lectures were very innovative and thought provoking, special effort was made by the lecturer to expose us to new ideas.'

'Lectures are very interesting because the wider scope of the issues and themes in the course, across different cultural backgrounds and perspectives.'

'Love, Family and Sexuality was the best subject I've done in my five years at university. I valued the opportunity to formulate my own theories, both individually and working as a group.' 


\section{University Library}

\section{- M M N E R VA A gateway to Melbourne's research publications}

Minerva Access is the Institutional Repository of The University of Melbourne

Author/s:

CHANG, JUI-SHAN

Title:

A trans-cultural wisdom bank in the classroom: making cultural diversity a key resource in teaching and learning

Date:

2006

Citation:

Chang, J.-s. (2006). A trans-cultural wisdom bank in the classroom: making cultural diversity a key resource in teaching and learning. Journal of Studies in International Education, 10(4).

Publication Status:

Inpress

Persistent Link:

http://hdl.handle.net/11343/34210 